\title{
Ubiquitous technologies for older people
}

\author{
Michela Cozza $^{1} \cdot$ Antonella De Angeli $^{2,3} \cdot$ Linda Tonolli $^{2}$
}

Received: 3 February 2015/Accepted: 19 December 2016/Published online: 14 February 2017

(c) The Author(s) 2017. This article is published with open access at Springerlink.com

\begin{abstract}
In this paper, we present a close reading of work in ubicomp of applications for older people. Starting from three lines of enquiry defined in the inaugural issue of this journal, we discuss how ubicomp research has presented the relationship between technologies and older users. We base our reasoning on a review of papers published in Personal and Ubiquitous Computing (1997-2014). The lines of enquiry refer to paradigms (functional vs. sociotechnical), users (stereotype and involvement), and contexts (indoor and/or outdoor). These themes address the presentation of SUITCASE project (SUstainable Integrated $\&$ Territorial CAre SErvices). This is a two-year research on care services for older citizens within the smart home construct. We develop an initial framework that not only provides a cohesive view of technologies for older people, but also serves as a salient guideline for reflective design which extends beyond the target population. This framework may also address future design projects, funding schemes, and editorial policies.
\end{abstract}

Keywords Assistive technology · Smart home · Sociotechnical paradigm $\cdot$ Stereotype

Michela Cozza

michela.cozza@mdh.se

1 School of Business, Society and Engineering, Mälardalen University, Högskoleplan 2, Gåsmyrevreten, 72123 Västerås, Sweden

2 Department of Information Engineering and Computer Science, University of Trento, Via Sommarive 9, Povo 2, 38123 Trento, Italy

3 School of Computer Science, University of Lincoln, Brayford Pool, Lincoln LN6 7TS, UK

\section{Introduction}

In the computer science literature, ageing has often been portrayed as a problem which requires technological solutions [58]. The rational is clearly stated. As people grow older, their physical and cognitive strengths fade out; technology provides the frame to support them at this stage of their lives. Recently, however, a few authors have challenged this rational warning us against stereotyping old age as problematic and challenging [58, 73]. They argue that current research may easily lead to a reinforcement of ageism and possibly discrimination. In this paper, we reflect on how the articles published in the journal of Personal and Ubiquitous Computing (PUC) have discussed older users. We ground our reflection on three themesparadigm, user, and context-identified in our reading of the editorial of the inaugural issue, dating back to 1997, when the journal was called Personal Technologies [19]. At the time, personal technologies were emerging and forcing a paradigmatic change that the journal embodied.

The editorial attributed the emphasis on "personal" rather than "portable" technology to a new, more encompassing research agenda. This paradigm was defined as "extending the role of computers into perhaps the most personal of all areas of life-social interaction and personal relationships" [19, p 2]. The authors thus envisioned a new venue for scientific and technical articles related not only to the technological but also to the social implications of the "whole range of personal systems supporting mobile and interactive work and also being carried into domestic contexts to support home and social life" [p 1]. Moreover, the editorial posed a number of questions to the emerging field. Two of them in particular have influenced our reflection: "Who will the new users be?" [p 3] and "Where will the killer contexts be?" [p 3].With reference to the first 
question, the authors suggest that "new user groups, such as families, children, students and the elderly, may become important. Which of these groups will drive the development of computing in the next millennium is a decisive factor, because products and services will be tailored to their own needs over and above those of other groups" [p 3 , our italics]. Addressing the second question, the editors identified not only mobile technologies but also "more personal contexts", such as clothes and bodies, as new challenges to face in the field of personal technologies.

This paper is a response to the recent calls for critical reflection on design practices (e.g. [9, 63]). We build our argument on different steps drawing from our research experience. We ground the paper, building on related work and describing the method applied to the analysis of the PUC paper (Sect. 2) along the enquiry lines of paradigm (Sect. 3), user (Sect. 4), and context (Sect. 5). We introduce our SUITCASE project (SUstainable Integrated \& Territorial CAre SErvices) as a case study of ubicomp development across these framing themes (Sect. 6), critically reflecting on our research results (Sect. 7). The discussion (Sect. 8) fosters the identification of new challenges for future research (Sect. 9).

\section{Grounding}

Over the recent years, a number of scholars from different disciplines, such as sociology (e.g. [47]), psychology (e.g. [64]), science technology and innovation studies (e.g. [52]), and gerontology (e.g. [30]) have paved the way for a new discussion about the relationship between ageing and technology. Scholars aligned with social gerontology research have been among the most critical voices $[31,52,73]$. These scholars have provided the intellectual tools to criticise mainstream computer science research, which portrays technology as a solution to many age-related problems. While arguing that this problem-solving perspective reinforces negative stereotypes about older people, they have emphasised heterogeneity and agency as important characteristics of older users.

The new movement challenged the mainstream stereotype of older people as socially, politically, and economically inactive subjects, in other words, as a burden on society. This opinion has been underlying ageing policies in North America and Europe over the last decades [6], inspiring a "rhetoric of compassion" [14] which emphasises the need for inclusion of, and equal opportunities for older people. In Europe, the trend dates back to the early nineties when the European Commission funded a series of initiatives for counteracting the effect of its rapidly ageing population [72, 74]. The rhetoric of compassion has affected the European ageing debate ever since, establishing a consolidated vision of the elderly as people requiring specific policy responses and technological solutions to help alleviate their problems.

\subsection{Related work}

Research in computer science mainly addressed ageing in connection to the development of assistive technology (AT). Beech and Roberts [5] identified three types of AT: supportive, responsive, and preventive technology. Supportive AT helps individuals to perform tasks that they may find difficult to perform on their own (e.g. medication reminder units). Responsive AT, based on detection and reaction, helps individuals to manage risks and raise alarms (e.g. panic buttons). Finally, preventive AT based on prediction and intervention mitigates dangerous situations and raises alarm (e.g. falls predictors). Ubicomp research embedded AT design within ambient assisted living (AAL) projects. AAL refers to "information and communication technology based products, services and systems to provide older and vulnerable people with a secure environment, improve their quality of life and reduce costs of health and social care" [12, $\mathrm{p}$ 253]. This view seems to chime in with the philosophy of "active ageing", emphasising the enhancement of quality of life of the elderly [81].

With reference to the literature that has contributed to the new discussion about the relationship between ageing and technology, we found some relevant monograph issues (e.g. $[29,51])$ and a few review articles (e.g. [14, 52, 73]). Such contributions criticised the recurrent framing in technology research according to which older people are a medical and economic problem [45, 79]. These authors claimed that this framing reflected the rhetoric of compassion associated with a "deficit-driven design" [57]. Looking for a different perspective, they introduce the idea of a new "rhetoric of engagement" [14] which could lead to a "positive design" [57]. Such a view fosters a proactive and integrated approach for counteracting the stereotypical image of older people. This change implies a comprehensive and preventive lifelong strategy of age management $[14,74]$.

Some authors claim that Human-Computer Interaction researchers (HCI) have largely been concerned with the downside of ageing [58]. Accordingly, they have contributed to the agenda which portrays the elders as people in need of technological solutions, instead of promoting their engagement with a view to empowerment. Other researchers [73] supported this argument with a discourse analysis of 30 years of ageing research published across the conferences sponsored by the ACM Special Interest Group on Computer-Human Interaction. These authors demonstrated that the community has mainly described ageing as a problem that can be managed with the help of 
technology. They attributed this tendency to the "prevailing societal and cultural attitudes (...) typically responsive to the aims of the funding bodies and governmental agencies that have commissioned the research" [73, p 2].

\subsection{Review methodology}

This theoretical framework motivated the systematic review of the Journal of Personal and Ubiquitous Computing that [73] did not consider in their review. We searched the Scopus database, which indexed only the current name of the journal from vol. 5(1) Feb. 2001 to vol. 18(8) Dec. 2014. We used the Collins Thesaurus for identifying the synonyms of the search keywords: Elder(s) (older person and senior), and Elderly (geriatrics, old people, OPAs, old-aged person, old-aged pensioner, pensioner(s), retired people, senior citizens, and wrinkles). The search was restricted to keywords, titles, and abstracts. The procedure was repeated on the Journal of Personal Technologies (1997-2000) in the Springer database.

No results were retrieved from the journal of Personal Technologies. A 45-article pool was retrieved from the PUC journal. All articles were reviewed and nine of them were discarded, as ageing was not their main focus. These papers indeed mentioned older people as one of the potential user groups, but they did not elaborate on agerelated issues. The selection was run independently by two authors of this paper, who later met to reconcile. A final pool of 34 papers was used for the purposes of our analysis. They were coded using the software ATLAS.ti and following the thematic analysis [11]. Paradigm, user, and context were used as main categories for the analysis. Table 1 lists selected papers.

\section{Paradigm}

The analysis enabled the identification of two prevailing research paradigms reflecting a functional or a sociotechnical perspective. The former portrays technology as a way of better managing the life of older people, both indoor and outdoor. The emphasis is on the technical evaluation of the solutions to user problems. Conversely, the sociotechnical paradigm frames the entanglement of social and material aspects, which affect the interaction between technologies and older people as users. Here, the emphasis is on the coconstruction of new design trajectories, which could deal with the diverse and changing conditions of older life. While the functional and the sociotechnical paradigms are not dichotomous, they define the boundaries of a more nuanced range of perspectives. Between the two extremes, there are seven papers that can be considered as hybrids, as they combine an emphasis on technology development (typical of the functional paradigm) with a user-centred approach (typical of the sociotechnical paradigm). The clustering of the papers between technical, hybrids, and sociotechnical is reported in Table 1. However, for the sake of convenience, in this paper we will mainly describe the two opposing poles.

\subsection{The functional paradigm}

Most articles associated with a functional paradigm follow a largely techno-centric perspective. The related projects are typically aimed at leveraging technologies to relieve/to alleviate/to mediate the difficulties of older life. Traces of this paradigm emerged for example in $[3,33,71,82]$. These papers share a common rigorous analysis of the technical properties and functional performance of system architectures. They assume that technology enables older people to lead an independent life [2]. They embrace Weiser's view [76] of technology as something that can blend into the background and becomes so seamlessly integrated into the environment that people do not event realise that they are using it. Accordingly, they described AT as pervasive [38], non-invasive, and non-intrusive [53] in the lives of (older) users. In the journal, we found several examples of AT development. Some of them referred to supportive technology (e.g. [20, 65]), other focused on responsive systems [27, 69] or preventive AT [39, 48].

The articles reflecting the functional paradigm are important in scoping the computational issues related to the ubicomp technology for older life. However, as several critics have pointed out [37, 49, 67], the functional paradigm reifies technology using an oversimplified model concerning the relationships between ICT and human actors. This model ignores the complex relationship between technology, history, and culture, and it encourages a technologically deterministic claim about the relationship between technology and older people.

\subsection{The sociotechnical paradigm}

The functional paradigm dominates the reviewed articles, but we identified seven contributions oriented towards a sociotechnical paradigm [10, 43, 44, 55, 56, 68, 78]. The sociotechnical paradigm is ideally situated at one end of a spectrum that has the functional view at the opposite extreme. Rather than focusing on the potential of technologies that can help older people to age well and perform better and/or assist caregivers to perform their duties faster and more easily, the sociotechnical paradigm puts the emphasis on the constitutive entanglement of technology and society. We borrow the metaphor of entanglement from the field of organisation studies [49], and more precisely from the scholars who describe the relationship 
Table 1 List of reviewed articles: years, author(s), title, paradigm: sociotechnical (S), functional (F), hybrids (H), user involvement: informative (I), consultative $(\mathrm{C})$, participative $(\mathrm{P})$, absent $(\mathrm{A})$; context: indoor $(\mathrm{I})$, outdoor $(\mathrm{O})$

\begin{tabular}{|c|c|c|c|c|c|}
\hline Year & Author(s) & Title & Paradigm & $\begin{array}{l}\text { User } \\
\text { involvement }\end{array}$ & Context \\
\hline 2002 & $\begin{array}{l}\text { Mikkonen M, Väyrynen S, Ikonen } \\
\text { V, M. O. Heikkilä }\end{array}$ & $\begin{array}{l}\text { User and concept studies as tools in developing mobile } \\
\text { communication services for the elderly }\end{array}$ & $\mathrm{S}$ & $\mathrm{P}$ & $\mathrm{O}$ \\
\hline 2004 & Harrison $\mathrm{CM}$ & Low-vision reading aids: reading as a pleasurable experience & $\mathrm{F}$ & A & I \\
\hline 2004 & Blythe MA, Wright PC, Monk AF & $\begin{array}{l}\text { Little brother: Could and should wearable computing } \\
\text { technologies be applied to reducing older people's fear of } \\
\text { crime? }\end{array}$ & S & I & I \\
\hline 2005 & $\begin{array}{l}\text { Szymkowiak A, Morrison K, } \\
\text { Gregor P, Shah P, Evans JJ, } \\
\text { Wilson BA }\end{array}$ & $\begin{array}{l}\text { A memory aid with remote communication using distributed } \\
\text { technology }\end{array}$ & $\mathrm{F}$ & $\mathrm{C}$ & $\mathrm{O}$ \\
\hline 2007 & West D, Quigley A, Kay J & MEMENTO: a digital-physical scrapbook for memory sharing & S & $\mathrm{I} / \mathrm{C}$ & $\mathrm{O}$ \\
\hline 2010 & $\begin{array}{l}\text { Dai J, Bai X, Yang Z, Shen Z, } \\
\text { Xuan D }\end{array}$ & Mobile phone-based pervasive fall detection & $\mathrm{F}$ & A & $\mathrm{O}$ \\
\hline 2010 & $\begin{array}{l}\text { van Kasteren TLM, Englebienne } \\
\text { G, Kröse BJA }\end{array}$ & $\begin{array}{l}\text { An activity monitoring system for elderly care using generative } \\
\text { and discriminative models }\end{array}$ & $\mathrm{F}$ & A & I \\
\hline 2010 & Vergados DD & $\begin{array}{l}\text { Service personalisation for assistive living in a mobile ambient } \\
\text { healthcare-networked environment }\end{array}$ & $\mathrm{F}$ & A & I \\
\hline 2010 & $\begin{array}{l}\text { Vassis D, Belsis P, Skourlas C } \\
\text { et al. }\end{array}$ & $\begin{array}{l}\text { Providing advanced remote medical treatment services through } \\
\text { pervasive environments }\end{array}$ & $\mathrm{F}$ & A & I \\
\hline 2010 & $\begin{array}{l}\text { Koufi V, Malamateniou F, } \\
\text { Vassilacopoulos G }\end{array}$ & $\begin{array}{l}\text { A system for the provision of medical diagnostic and treatment } \\
\text { advice in home care environment }\end{array}$ & $\mathrm{F}$ & A & I \\
\hline 2010 & Bekker T, Sturm J, Barakova E & $\begin{array}{l}\text { Design for social interaction through physical play in diverse } \\
\text { contexts of use (Editorial) }\end{array}$ & l & I & l \\
\hline 2010 & $\begin{array}{l}\text { Bamis A, Lymberopoulos D, } \\
\text { Teixeira T et al. }\end{array}$ & $\begin{array}{l}\text { The BehaviorScope framework for enabling ambient assisted } \\
\text { living }\end{array}$ & $\mathrm{H}$ & $\mathrm{I} / \mathrm{C}$ & $\mathrm{I} / \mathrm{O}$ \\
\hline 2010 & Vanden Abeele V, Schutter BD & $\begin{array}{l}\text { Designing intergenerational play via enactive interaction, } \\
\text { competition, and acceleration }\end{array}$ & $S$ & $\mathrm{C}$ & I \\
\hline 2011 & $\begin{array}{l}\text { Hynes M, Wang H, McCarrick E } \\
\text { et al. }\end{array}$ & $\begin{array}{l}\text { Accurate monitoring of human physical activity levels for } \\
\text { medical diagnosis and monitoring using off-the-shelf cellular } \\
\text { handsets }\end{array}$ & $\mathrm{F}$ & A & $\mathrm{O}$ \\
\hline 2011 & $\begin{array}{l}\text { Munõz A, Augusto JC, Villa A, } \\
\text { Botía JA }\end{array}$ & $\begin{array}{l}\text { Design and evaluation of an ambient assisted living system } \\
\text { based on an argumentative multi-agent system }\end{array}$ & $\mathrm{F}$ & $\mathrm{I} / \mathrm{C}$ & I \\
\hline 2011 & $\begin{array}{l}\text { Lézoray JB, Segarra MT, Phung- } \\
\text { Khac A et al. }\end{array}$ & $\begin{array}{l}\text { A design process enabling adaptation in pervasive } \\
\text { heterogeneous contexts }\end{array}$ & F & A & I \\
\hline 2011 & $\begin{array}{l}\text { García-Vázquez JP, Rodríguez } \\
\text { MD, Andrade AG et al. }\end{array}$ & $\begin{array}{l}\text { Supporting the strategies to improve elders' medication } \\
\text { compliance by providing ambient aids }\end{array}$ & $\mathrm{H}$ & I & $\mathrm{O}$ \\
\hline 2011 & $\begin{array}{l}\text { Walter M, Eilebrecht B, Wartzek } \\
\text { T et al. }\end{array}$ & $\begin{array}{l}\text { The smart car seat: personalised monitoring of vital signs in } \\
\text { automotive applications }\end{array}$ & $\mathrm{F}$ & A & $\mathrm{O}$ \\
\hline 2011 & $\begin{array}{l}\text { Almeida A, Orduña P, Castillejo } \\
\text { E. et al. }\end{array}$ & $\begin{array}{l}\text { Imhotep: an approach to user and device conscious mobile } \\
\text { applications }\end{array}$ & $\mathrm{F}$ & A & $\mathrm{O}$ \\
\hline 2013 & Kim SC, Jeong YS, Park SO & $\begin{array}{l}\text { RFID-based indoor location tracking to ensure the safety of the } \\
\text { elderly in smart home environments }\end{array}$ & $\mathrm{F}$ & A & I \\
\hline 2013 & $\begin{array}{l}\text { Fontecha J, Navarro FJ, Hervás R } \\
\text { et al. }\end{array}$ & $\begin{array}{l}\text { Elderly frailty detection by using accelerometer-enabled } \\
\text { smartphones and clinical information records }\end{array}$ & $\mathrm{H}$ & $\mathrm{C}$ & $\mathrm{O}$ \\
\hline 2013 & Ayala I, Amor M, Fuentes L & Self-configuring agents for ambient assisted living applications & $\mathrm{F}$ & A & $\mathrm{O}$ \\
\hline 2013 & Planinc R, Kampel M & Introducing the use of depth data for fall detection & $\mathrm{F}$ & A & I \\
\hline 2013 & $\begin{array}{l}\text { Maekawa T, KishinoY, Sakurai Y } \\
\text { et al. }\end{array}$ & Activity recognition with hand-worn magnetic sensors & $\mathrm{F}$ & A & $\mathrm{O}$ \\
\hline 2013 & $\begin{array}{l}\text { Portet F, Vacher M, Golanski C } \\
\text { et al. }\end{array}$ & $\begin{array}{l}\text { Design and evaluation of a smart home voice interface for the } \\
\text { elderly: acceptability and objection aspects }\end{array}$ & S & $\mathrm{C}$ & I \\
\hline 2013 & $\begin{array}{l}\text { Rodríguez MD, Roa JR, Morán } \\
\text { AR et al. }\end{array}$ & $\begin{array}{l}\text { CAMMInA: a mobile ambient information system to motivate } \\
\text { elders to exercise }\end{array}$ & S & $\mathrm{I} / \mathrm{C}$ & $\mathrm{O}$ \\
\hline 2013 & Meza-Kubo V, Morán AL & $\begin{array}{l}\text { UCSA: a design framework for usable cognitive systems for } \\
\text { the worried-well }\end{array}$ & S & $\mathrm{I} / \mathrm{C}$ & I \\
\hline
\end{tabular}


Table 1 continued

\begin{tabular}{|c|c|c|c|c|c|}
\hline Year & Author(s) & Title & Paradigm & $\begin{array}{l}\text { User } \\
\text { involvement }\end{array}$ & Context \\
\hline 2014 & $\begin{array}{l}\text { Ordóñez FJ, de Toledo P, Sanchis } \\
\text { A }\end{array}$ & $\begin{array}{l}\text { Sensor-based Bayesian detection of anomalous living patterns } \\
\text { in a home setting }\end{array}$ & $\mathrm{H}$ & I & I \\
\hline 2014 & Han K, Jung M, Cho J & $\begin{array}{l}\text { Implementation of the personal healthcare services on } \\
\text { automotive environments }\end{array}$ & $\mathrm{F}$ & A & $\mathrm{O}$ \\
\hline 2014 & Yuan B, Herbert J & $\begin{array}{l}\text { Context-aware hybrid reasoning framework for pervasive } \\
\text { healthcare }\end{array}$ & $\mathrm{F}$ & A & I \\
\hline 2014 & Park RC, Jung H, Shin DK et al. & $\begin{array}{l}\text { Telemedicine health service using LTE-Advanced relay } \\
\text { antenna }\end{array}$ & $\mathrm{F}$ & A & $\mathrm{O}$ \\
\hline 2014 & Kim YH, Lim IK, Lee JK & $\begin{array}{l}\text { A study on algorithm to identify the abnormal status of a } \\
\text { patient using acceleration algorithm }\end{array}$ & $\mathrm{H}$ & A & I \\
\hline 2014 & $\begin{array}{l}\text { Poulymenopoulou M, } \\
\text { Malamateniou F, } \\
\text { Vassilacopoulos G }\end{array}$ & E-EPR: a workflow-based electronic emergency patient record & $\mathrm{F}$ & A & $\mathrm{I} / \mathrm{O}$ \\
\hline 2014 & $\begin{array}{l}\text { Maglogiannis I, Betke M, } \\
\text { Pantziou G }\end{array}$ & $\begin{array}{l}\text { Assistive environments for the disabled and the senior citizens: } \\
\text { theme issue of PETRA } 2010 \text { and } 2011 \text { conferences } \\
\text { (Editorial) }\end{array}$ & I & I & I \\
\hline
\end{tabular}

between the social and the material world as characterised by inseparability, interpenetration, relationality, and embodiment [13].

The sociotechnical paradigm assumes that technology designed for (older) users consists of social and technical systems interacting with an external environment (where people live or work). Optimal performances can only be expected if there is a balance between the systems [4]. In fact, the meaning of technical artefacts is the result of social interactions (among designers, developers, users, and stakeholders), and not defined from the intrinsic properties of these artefacts. Different social actors can thus interpret them differently [7]. The definition of active ageing can be reformulated from a sociotechnical perspective as "a comprehensive strategy to maximise participation and well-being as people age. This strategy should operate simultaneously at the individual (lifestyle), organisational (management) and societal (policy) levels and at all stages of the life course" (Walker, quoted in 74, p S126).

Blythe et al. [10] presented an explicit example of a sociotechnical research applied to the design of wearable technology for reducing fear of crime among older people. The meaning of technology was framed into an ethnographical process of acquiring knowledge about possible users and contexts. As a result, the authors problematised terms such as "fear", "crime", and "older people". The ethnographical data were also translated into design artefacts (as in [78]). In this process, material and technological performances became meaningful in relation to their social situatedness [66] and, vice versa, the user behaviour became meaningful in relation to technology (as in [44]). Similarly, Meza-Kubo and Morán [43] applied a usercentred design approach in order to develop usable cognitive training systems for older people, starting from their actual needs that, in turn, shaped the design framework. This article enables us to discuss another property of the sociotechnical paradigm, which concerns the understanding of technology not only as computing architectures (de-contextualised and empty of human actors, cultural values, and social implications), but also as complex infrastructures that articulate processes (i.e. the functioning of devices or the user experience) and practices (i.e. design activities, caregiver duties, and user daily practices) bringing together contexts, humans, and things [55, 56, 68].

\section{User}

Our second line of enquiry concerns the understanding of older people as technology users. Following this line, we identified two main themes describing how older people were portrayed in the research (stereotypes) and the types of methodologies, which inspired user research (involvement) [79]. Stereotypes are cognitive structures containing knowledge, expectations, and beliefs about what other people should be like and how they ought to behave [24]. While the term often evokes negative connotations, stereotypes serve at least two useful functions in tasks involving social cognition, including design. Firstly, they allow humans to categorise similarities and differences between themselves and others, favouring in-group cohesion and a sense of identity. Secondly, they act as judgemental heuristics, saving time and cognitive effort. Stereotypes, however, are often derogatory towards members of out-groups and are an important aspect of prejudice, discrimination, and hostility towards other people [1]. 


\subsection{Stereotypes}

As age (along with race and gender) is a primary social category, age stereotyping is automatic or formulated too quickly to be thoughtful and deliberate [8]. Research in social psychology contends that age stereotyping starts from a general categorisation based on physical traits (grey hair, hair loss, hearing loss, and poor sight) and then articulates into a number of specific stereotypes, depending on the personality traits and behaviour considered. Lack of competence (being it physical, social, or emotional) is a distinctive attribute of age stereotyping applied to interpret the behaviour of older people in several life domains. On a positive note, older people are often perceived as warm. Stereotypes, as each type of categorisation, are a simplification of the real world. In fact, one sociotechnical article stresses that "older people are not a homogenous group: they do not live in the same places, they do not have access to the same resources, and they do not have the same abilities" [10, p 403]. Similarly, in another article we read that a design-for-all approach may be inappropriate given that each person has specific needs [55].

The review revealed that older people's heterogeneity is largely ignored, mostly among functional studies. When considered, heterogeneity relates to diseases, capabilities, and habits and serves a functional purpose. In [38], for example, we found a reference to the concept of elderly "heterogeneity", followed by the technical proposal of "adaptation". In the introduction, the authors claim that most technological applications are either too general or too specific. Indeed, each older person has specific health concerns, capabilities, and habits and the deployment environment may be different from one instance to the other. Similarly, the needs of older people evolve over time and so does the deployment environment. Therefore, proposing an overly general or specific application is not a satisfying solution as it may lead to a rejection of the application by the final user, or an inadequate deployment. This work is interesting, but it only proposes a technological solution to compose and modularise the complexity of the context of use, disregarding the sociotechnical implications of heterogeneity.

Reductionism is common among the articles, which presented nuanced versions of the negative side (incompetent) and the positive side (warm) of the stereotype. McLean [42] noticed that many studies are focused on negative stereotypical attributions such as frailty, dependence, inactivity, incompetence, and high resource consumption (e.g. [18]). For example, Vergados maintained that "the elderly population can be practically considered as a pool of patients" [71, p 575] treating "elderly" and "patients" as synonyms throughout the paper. This vision associates ageing with an increase in costs $[33,75]$ and considers technology as a primary means to reduce the economic impact of the ageing population. For instance, building on the stereotype which attributes memory lapses to stable conditions in older life, Szymkowiak et al. [65] suggested the development of several electronic memory aids. In this work, they echoed Vergados specifying that such technology was targeted to "non-average (population), e.g. the elderly or memory-impaired users" [p 2].

Only a few studies (e.g. [68]) moved away from the negative stereotype of senior life, exploring its more positive aspects, which include fun. Vanden Abeele and De Schutter's work [68] is particularly interesting, as it presented a digital game aimed at facilitating knowledge transfers between youngsters (aged between 7 and 10) and seniors (aged 65 or older). The game was designed with a player-centred approach, involving seniors and youngsters throughout the entire process.

\subsection{User involvement}

An important theme regards the level of user involvement, considering older people and other stakeholders who are influenced by technology at use or design time. Drawing upon an extensive literature, Iivari and Iivari [28] define user involvement as one important dimension for evaluating methods and approaches of system development. They argue that user involvement is a "state reflecting the importance and the relevance a user attaches to a given system" [p 133].

Enquiring into the text and asking how users were involved in the design process, we analysed the papers according to the user role. Following Damodaran [17], we differentiated between an informative role (users act as providers of information and as objects of observation), consultative role (users are allowed to comment on predefined design solutions), or participative role (users actively take part in the design process and can make decisions about solutions). This categorisation suggested that the research presented in the PUC journal is often satisfied with an informative and a consultative user involvement. In fact, among the few sociotechnical contributions, we found only one exceptional narrative about a participative users' role [44].

Many studies embracing the functional paradigm adopt an informative role. Here, involvement is usually restricted to data collection through interviews and observations, as in Blythe et al. [10]. In some articles, older people are not involved and researchers use information generated by "surrogates" such as research colleagues (e.g. [33]), students and mannequins (e.g. [16]), or other people contacted through convenience sampling (e.g [26]) involved older people but also their friends and family members. With the exception of the mannequins used in physical probes, all 
other surrogates are assumed to have, or to be able to acquire, a good understanding of the users and their habits.

At times, the consultative and the informative roles coexist in the same article, as in [78], where older people were involved in an ethnographic study using a cultural probe to gather information on memory sharing activities at home (informative role). In a successive study, seven younger participants were recruited to interact with a prototype in order to evaluate usability. The authors justified their methodological choice stating that it was the first user study with the prototype. As a consequence, they preferred to involve "participants who are more likely to learn quickly and be flexible" and, more importantly, they needed "users who would not be confused or distracted by the system delay" [p 320].

The paper by Mikkonen et al. [44] is the closest to the Scandinavian tradition of participatory design. The authors presented a concept study aimed at finding out the key service needs of older people. These needs were gathered from the final users and from the experts applying participatory design approaches in the ideation sessions. However, the authors specified that the services created and tested in their study were dealt with only at the conceptual level. This is a frequent limitation of research pursued from a sociotechnical perspective.

\section{Context}

AAL can offer many older people the possibility of living independently at home. According to Cardinaux et al. [12], AAL can benefit individuals, communities, and working environments. The articles about the development of AAL for older users are evenly split between indoor (18 articles) and outdoor contexts (16 articles). Two articles discussed technologies that fall in both groups $[3,54]$.

\subsection{Indoor}

Innovation in AAL aims to build "smart homes" as living spaces equipped with various technologies for monitoring their inhabitants while fostering an independent lifestyle and health preservation [20]. Smart technology at home can be of special interest for older people living alone. The literature review revealed that ubicomp research enquired into several "smart home" issues in the past decade. Most of these studies followed a functional paradigm to shed some light on technologies and their role in assisting older people at home. More precisely, technologies for indoor environments were associated to age-related cognitive [70] or physical impairment (e.g. [26, 35]), or they were developed to detect dangerous situations such as falls [53] or anomalous living patterns [34, 48]. In recent years, however, this functional view has attracted some criticism, claiming that it contributed to the commercial failure of the smart home paradigm [80].

Smart homes form connections and networks that some authors have conceptualised as "information ecologies" [40]. This concept stresses the situated entanglement between (older) people (their values and behaviours) and technologies. A sociotechnical reading, which could inform our understanding of technologies and human activities that benefit from them [46], is still missing in the PUC literature. Among the sociotechnical articles, we found only one paper specifically devoted to smart homes [55]. The authors presented a project aimed at developing a user-friendly technology for home automation based on voice command. The paper reports a user evaluation assessing acceptance and fear of this new technology. Eight healthy individuals aged between 71 and 88, seven relatives (child, grandchild, or friend) and three professional carers participated in the evaluation. Analysing the data, the authors clarified their objective as the development of "a system to improve security and comfort that can be continuously adapted to the person's degree of autonomy throughout (his-) her life" [p 131, our italics]. This attention to heterogeneity is also evident in the already discussed contribution by Vanden Abeele and De Schutter [68]. Their work is exemplary not only because it reflects a positive view of the older users, but also because it sketches an image of the homes as a playful (rather than merely smart) places. From their perspective, homes become really "smart" by virtue of the learning processes they host.

In conclusion, the PUC literature depicts an image of home and indoor environments ranging from a negative to a positive pole. This continuum resembles the bi-polarity of age stereotypes. Once again, the negative stereotypes prevail.

\subsection{Outdoor}

The concept of ubiquity emphasises the embeddedness of computing in everyday life, and the ubicomp era is "fundamentally characterised by the connection of things in the world with computation" [77]. Research on mobile and wearable systems has attracted much attention in recent years. Accordingly, starting from volume 15 (2011) the PUC literature confirmed a growing interest in mobile and wearable technology for older people. In this volume, García-Vázquez et al. [20] described some mobile systems that are relevant to personal medication management. Following a functional paradigm, the authors focused on the description of the systems. Such technologies were developed with the involvement of older users at the beginning (requirement phase) and at the end (summative 
evaluation). This iteration is typical of the user-centred functional paradigm.

We compared the paper of García-Vázquez et al. [20] with that of Rodríguez et al. [56]. They presented the results of a case study about the factors that enable the elderly to keep a regular exercise routine. While these two contributions are both aimed at designing persuasive technologies to motivate older people to do something that they would not do of their own accord, they differ on many levels. Rodríguez and colleagues embrace a sociotechnical paradigm: older users were interviewed and involved in workshops to identify issues for design. In this process, the user involvement increased from an informative to a participatory role.

Overall, mobile or outdoor technologies for older people are discussed more often within the functional paradigm than within the sociotechnical one. The substantial effort required by the development of wearable sensors [39], smart devices [25], or advanced technological infrastructures [50] deters the authors from involving older users throughout the design process, which would entail an additional effort.

\section{Research experience}

We use the results of the literature review to show how the three-part framework (paradigm, user, and context) is applicable to the design and development of ubiquitous computing projects. For this purpose, we introduce a case study that refers to the SUITCASE project started in 2013. SUITCASE was an Italian pre-commercial procurement aimed at developing innovative services for the welfare of citizens in their own homes, with a focus on older people. Project partners included business partners (several companies developing the IT outputs), research partners (the Economy, Sociology and Computer Science departments of University of Trento), and a sponsor (a Public Innovation Cluster). We describe the project according to the three lines of enquiry.

- Paradigm SUITCASE is a hybrid case study showing the potential and complexity of the combination of technical and economic interests, with participatory and engaging activities. According to the funding scheme, the commercialisation of the developed care technologies and services was the priority. The attention to the social aspects was delegated to the design researchers who based their action plan on a participatory approach. On this perspective, the project challenged the design tradition by enacting a participatory process on a large scale. In fact, participatory design initiatives usually work on a small scale for the purpose of favouring people engagement with design project [15]. Though ambitious, such a scaling-up was promising. The purpose was the construction of a sociotechnical infrastructure through which people could effectively interact according to their own needs. This infrastructure rested on a public-private consortium within which the heterogeneity of interests (economic, scientific, and social) complicated the interaction.

- User The project was foregrounded by the prevailing stereotype of the elderly as people in need. However, the research approach enabled the evolution from an informative to a participative role of the older users. Research activities involved a group of volunteers interested in participating in the development and testing of services. The objective was to reach a sample of 120 older people by the end of the project. Volunteers were selected with the help of a group of stakeholders (i.e. local associations and cooperatives). The user profile referred to healthy, over 65 participants, living in the urban area of Trento, Italy. People were invited to experiment new technologies through several participatory activities. We expected these people to have practical requirements (e.g. transport and tele-monitoring) and psychological needs (e.g. socialisation opportunities to decrease loneliness).

- Context The project aimed to develop different services for improving the conditions needed for people to live safely and independently for as long as possible at home. The technical component of the smart home was realised using a commercial environmental sensor network that communicated by way of with the backend by an Android set-top box, connected to ADSL and TV. The box collected and processed incoming data. When the alert thresholds about a certain event (e.g. carbon monoxide level) exceeded a certain limit, the system triggered a set of predefined operating procedures. The home services were provided for free throughout the whole experimentation process. Older people who joined the project agreed to have their home equipped with the technological devices. They were shortly instructed on how they worked, and given a one-page manual. A toll-free number was at their disposal for any questions or doubts.

\subsection{Research methods}

The core objective of the research was to construct a sociotechnical infrastructure by applying a participative methodology. Research partners engaged the volunteers in the design of care technologies and services. Due to the cost-saving approach of the funding bodies, the co-design activities entailed the adjustment of technologies available 
on the market. Several activities were performed that gradually increased the level of user involvement.

- Personal diaries Twenty older people were invited to keep a diary reporting any critical event which occurred in their everyday lives for a two-week period [59]. Participants were given a form titled Problem Mapping, structured into a list of dimension (e.g. home, security, financial management, mobility, social relations, and health). Furthermore, they were invited to answer a set of questions, addressing what was literally defined as the problem and the solution.

- Semi-structured interviews A sample of 19 volunteers (16 women and 3 men aged between 68 and 90) were interviewed by one of the authors in a private room at a local association. She enquired into the interviewees' daily life and leisure activities, or constraints, also focusing on possible critical events. Each interview was audio-recorded and completely transcribed, using fictive names to protect anonymity. The software ATLAS.ti supported the coding process following grounded theory rationale [22].

- Scenario-based design Four design meetings based on the approach proposed by [36] were held. They involved nine older people divided into two groups in order to discuss 11 scenarios, each of which was focused on one possible project service. The groups each were met by two researchers. One played the role of the ethnographer who took field notes and made photographs, and the other acted as facilitator who led the discussion interactively.

- Contextual interviews Eight contextual interviews [59] were enacted in the homes of the participants, equipped with an evolving prototype of the "smart home" solution. Five users provided feedback on the initial prototype leading to a number of changes, which were implemented and evaluated by a new sample of three users. Each interview was structured as a face-to-face meeting between two researchers and the older person. The researchers watched the users while they interacted with the technologies and discussed emerging issues with them.

\subsection{Methodological reflections}

The range of interventions slowly increased the level of user involvement. The diary study involved older people as informants. The interviews furthered their involvement, allowing them to fulfil a more consultative role and increasing their psychological attachment to the project. The scenario-based intervention also increased the level of user participation, but the information provided was still mainly based on self-reports, and detached from the context of use. Finally, the contextual interviews increased involvement by grounding the user participation in the context of use. However, both the hybrid nature of the project, and the complex multiparty collaboration challenged our effort to facilitate the participation. Taking a reflexive stance [9,62], we could say that our research interventions did not translate exactly the Scandinavian participatory design principles [32]. In fact, the older users' influence on the decision-making process was limited by the functional paradigm. Furthermore, the functionalities of the existing systems were difficult to modify, which limited the degree to which the participants could benefit from the co-design approach. Nevertheless, this project presented a mature implementation of the user-centred principles [23] within a sociotechnical paradigm.

\section{Research results}

Overall, the results of the design raised a number of issues, which can be summarised considering: (1) the entanglement of the paradigm and the user and (2) the entanglement of the user and the context.

\subsection{Paradigm and User}

The functional root of the project is well displayed by the results of the personal diaries. They represented the first activity for involving the older people. After two weeks, only five users returned their diaries, which were substantially left unanswered, or filled with comments about the incompatibility between the task requirements and the elderly life. As a representative example of this tendency one user wrote: "I read very carefully all the questions, but fortunately I can tackle all these problems by myself". The few criticalities reported in the diaries reflected an image of active people, capable of solving everyday challenges autonomously and confidently.

This portrait was confirmed by the data gathered through the semi-structured interviews. They worked as icebreakers for the friendly approach of the participants, providing a rich and diverse set of knowledge about the user sample. Overall, the interviews contributed to creating a deeper psychological involvement in the project [28]. They constituted a new starting point allowing to frame possible users' needs in their everyday lives. Some interviewees spontaneously commented on the diaries, like Arianna, who said:

With that diary... what we would have to write?... In short, they are all little things that are not so important to write... as a consequence all of us have given up... no one has written anything... do you understand what I mean? But an interview... no problem... 
to tell... I'm able to speak... it seems strange to me that I have to write... stuff that others might be interested in reading ... this is just my daily life.

To understand the failure of the diaries, we analysed the applied method. Such a critical reflection disclosed the functional paradigm entailed by the form of the diary. The participants were invited to comment on a set of problems stereotypically related to old age. The elderly were portrayed as frail people with special needs. This problemsolving perspective matched the idea of technologies as effective solutions to age-related impairments. On a practical level, such a framework conflicted with the actual experience of the participants. On the one hand, the diary dismissed the heterogeneity of the target population. On the other hand, it ignored the wide range of resources that the participant could rely on to tackle possible problems.

The stereotyped form of the diary reduced the participants' involvement, whereas the interviews opened a design space. Explicitly, the interviewees referred their initial lack of commitment to the choice of an unsuitable tool (i.e. the diary). Implicitly, they highlighted the designers' bias. Conversely, drawing on the semi-structured interviews, we realised that the needs of the elderly were not so different from those of most human beings. In accordance with Maslow [41], we identified the needs of "love/belonging", "esteem", and "self-actualization". Other concerns mainly referred to "safety" rather than physiological issues. A careful analysis of the data revealed that, if people stay healthy, active, and autonomous as they age, ageing is not necessarily a negative time of life. For sure, older life is not free of limitations or constraints, as life in general is not. However, the interviews confirmed that an age-based categorisation frequently leads to negative stereotyping.

The critical reflection provided useful insights into possible improvement strategies [21]. The interviews clearly highlighted the limitations of a functional approach to the age-related issues. After the semi-structured interviews, we involved older users as much as possible with the design scenarios and the contextual interviews. The design scenarios enabled people to show their creativity, while the contextual interviews allowed us to shed some light on key issues related to the privacy of the location. A participatory approach was the main condition that enable an iterative design, calling attention to the constitutive relationships between the technologies and the users.

\subsection{User and context}

The problematic entanglement of the social and technical aspects came up throughout the project. The main issues concerned context awareness $[60,61]$, that is, how pervasive technologies reacted to environmental changes. Such variability was often wrongly elaborated by technologies that consequently failed. The environmental sensors of the smart home solution displayed the most critical functioning, as Giulietta reported:

A month ago the operators called me twice because according to them there was a leak of gas at home. It was 8 in the morning and I said "no, everything is normal here". I explained that I have a small apartment; many times my son sleeps here [in the kitchen] because here there is a bed [a cupboard-bed]. So, having two people in 44 meters, probably the oxygen lacks in the morning.

This is a typical example of technological invasiveness in the users' private life. The environmental sensors recorded a risky situation at home, and the system triggered the standard operating procedure. Accordingly, Giulietta exposed some personal information to the Service Dispatcher, which may have caused her some embarrassment. Throughout the project, we encountered other similar situations. Some people elaborated on this point, explicitly telling us about the perceived technological intrusion, as Margherita did:

Initially, this flashing stuff [the LEDs of the smart box] bothered me so much... To be honest, I felt a sense of anxiety because I felt spied on. [In our society] we all are, but knowing that in my house there is something which controls the parameters bothered me at first. It was like an intruder in my nest, which controlled what I did. This is the other side of the coin in this project. I want to feel safe, but basically I feel under control.

The interaction with the participants drove our critical reflection beyond the project, towards the wider field of design research.

\section{Discussion}

In this paper, we have proposed three lines of enquiry, which can be used as analytical tools to foster reflection on technological research. They refer to the paradigm, the user, and the context. Through a systematic review of the literature on technology for older users published in the PUC journal, we have identified a set of important themes related to each line. The emerging framework is summarised in Table 2.

Results from the PUC review reflects recent considerations about research on elderly people in general [31], and design in particular $[14,57,73,79]$. Reviewed papers put a strong emphasis on the functional paradigm, which 
Table 2 A framework for critical reflection on design practices

\begin{tabular}{lll}
\hline Paradigm & $\begin{array}{l}\text { Functional } \\
\text { Hybrid } \\
\text { Sociotechnical }\end{array}$ & \\
\hline User & Stereotypes & Negative \\
& Positive \\
& & Informative role \\
& & Consultative role \\
Context & Indoor & Participative role \\
& Ossistance \\
& Outdoor & Empowerment \\
& & Assistance \\
& & Empowerment \\
\hline
\end{tabular}

substantially affected the narrative about users and contexts. Accordingly, older users were defined by enduring attributions of frailty and dependency, as well as by a notable absence of heterogeneity and active engagement. Furthermore, a bipolar representation of the context emerged, indoor and outdoor being mainly described as places where older people could be assisted rather than empowered.

We applied this framework to the analysis of a hybrid case study of ubicomp deployment for older citizens. This exercise demonstrated the strong entanglement between the three main lines of enquiry. The project tried to reconcile a functional paradigm — supported by the funding agency and deeply engrained in the available artefacts-with a sociotechnical research interest. Such integration proved challenging but promising. From one perspective, the functional paradigm ensured the development and delivery of new services. Another perspective, the sociotechnical, exposed several negative stereotypes on older users [8] and counteracted them through progressive steps of user involvement [28]. Working with the users and establishing a relationship of mutual trust and respect with them, we attempted to reconcile the simplification required by technology development with the intrinsic heterogeneity of users and contexts.

Critical reflection is instrumental to ethical design because it brings "unconscious aspects of experience to conscious awareness, thereby making them available for conscious choice" [63, p 50]. The framework presented in this paper can be used to stimulate thoughtful questions about design practices, and thus foster reflexivity (i.e. the ability of reflecting on one's own practices) [63]. These questions address epistemology, methodology, techniques, and tools. While acting reflexively, researchers can understand how the paradigm affects both the user engagement and the context of use. The analysis unfolds through a double reflexive movement, including a phase of "zooming in on" and a phase of "zooming out from" the three lines of enquiry. Zooming in addresses paradigm, user, and context as separated and independent dimensions, while zooming out makes the connections between these dimensions evident. This reflexive movement can complement the traditional user-centred design process (establishing requirements, designing alternatives, prototyping, and evaluating) for a variety of different design projects-over and above the case of older users.

This framework could also be relevant to the evaluation of a larger range of funding [6] and, arguably, of editorial policies. It is indeed evident that both factors influence the scientific work. Increasingly, the funding schemes supporting ICT research tend to reward projects aimed at developing new technologies, while they underestimate the importance of sociotechnical studies [49]. Such an attitude also pervades editorial decisions, but the increasing number of hybrid papers published in the last few years in the PUC journal suggests a promising move towards more reflexive contributions in the ubicomp field.

\section{Conclusion}

In this paper, we have presented an initial framework to drive critical ubicomp research addressing older users. This interest echoes the inaugural issue of this journal [19], when the editors identified the "elderly" among the diverse actors who could drive the future development of computing. The prediction has been only partially fulfilled, as research addressing older people is still a minority and older people have limited influence on it. Excluding older users from building their future may reinforce ageism and even discrimination. Our contribution suggests an approach entailing a double reflexive movement of zooming in on and zooming out from three framing themes: the paradigm, the user, and the context. Future work should benefit from applying such a reflexive lens to the evaluation of design, funding, and editorial decisions on ubiquitous computing research.

Acknowledgements SUITCASE (SUstainable Integrated \& Territorial CAre SErvices) was funded by TRENTO RISE. The work reported in this paper was partially supported by "ACANTO: A CyberphysicAl social NeTwOrk using robot friends" (H2020) and "Active Ageing @home" (MIUR Technological Cluster). We thank Costanza Vettori for her editorial help.

Open Access This article is distributed under the terms of the Creative Commons Attribution 4.0 International License (http://crea tivecommons.org/licenses/by/4.0/), which permits unrestricted use, distribution, and reproduction in any medium, provided you give appropriate credit to the original author(s) and the source, provide a link to the Creative Commons license, and indicate if changes were made. 


\section{References}

1. Ashmore RD, Del Boca FK (1981) Conceptual approaches to stereotypes and stereotyping. Cognitive Process Stereotyping Intergroup Behav 1:35

2. Ayala I, Amor L, Fuentes L (2013) Self-configuring agents for ambient assisted living applications. Pers Ubiquit Comput 17:1159-1169

3. Bamis A, Lymberopoulos D, Teixeira $T$ et al (2010) The BehaviorScope framework for enabling ambient assisted living. Pers Ubiquit Comput 14:473-487

4. Bannon L, Ehn P (2013) Design matters in participatory design. In: Simonsen J, Robertson T (eds) Handbook of participatory design. Routledge, New York, pp 37-63

5. Beech R, Roberts D (2008) Assistive technology and older people. SCIE Research briefing 28. http://www.scie.org.uk/publica tions/briefings/files/briefing28.pdf

6. Biggs S (2001) Toward critical narrativity. Stories of aging in contemporary social policy. J Aging Stud 15:303-316

7. Bijker WE (1995) Of bicycles, bakelites, and bulbs: toward a theory of sociotechical change, inside technology. The MIT Press, Cambridge

8. Blaine BE (2013) Understanding the psychology of diversity, 2nd edn. Sage, Thousand Oaks

9. Blomberg J, Karasti H (2013) Ethnography. Positioning ethnography within participatory design. In: Simonsen J, Robertson T (eds) Handbook of participatory design. Routledge, New York, pp 86-116

10. Blythe MA, Wright PC, Monk AF (2004) Little brother: could and should wearable computing technologies be applied to reducing older people's fear of crime? Pers Ubiquit Comput 8:402-415

11. Braun V, Clarke V (2006) Using thematic analysis in psychology. Qual Res Psychol 3:77-101

12. Cardinaux F, Bhowmik D, Abhayaratne C et al (2011) Video based technology for ambient assisted living: a review of the literature. J Ambient Intell Smart Environ (JAISE) 3:253-269

13. Carlile PR, Nicolini D, Langley A et al (eds) (2013) How matter matters. Objects, artifacts, and materiality in organization studies. Oxford University Press, Oxford

14. Carroll JM, Convertino G, Farooq U et al (2012) The firekeepers; aging considered as a resource. Univ Access Inf Soc 11:7-15

15. Clement A, Van den Basselard P (1993) A retrospective look at PD projects. Commun ACM 36:29-37

16. Dai J, Bai X, Yang Z et al (2010) Mobile phone-based pervasive fall detection. Pers Ubiquit Comput 14:633-643

17. Damodaran L (1996) User involvement in the systems designs process-a practical guide for users. Behav Inf Technol $15: 363-377$

18. Fontecha J, Navarro FJ, Hervás R et al (2013) Elderly frailty detection by using accelerometer-enabled smartphones and clinical information records. Pers Ubiquit Comput 17:1073-1083

19. Frohlich D, Thomas $P$, Hawley $M$ et al (1997) Inaugural issue editorial: future personal computing. Pers Technol 1:1-5

20. García-Vázquez JP, Rodríguez MD, Andrade AG et al (2011) Supporting the strategies to improve elders' medication compliance by providing ambient aids. Pers Ubiquit Comput 15:389-397

21. Gaver W, Bowers J, Kerridge T, Boucher A et al (2009) Anatomy of a failure. How we knew when our design went wrong, and what we learned from it. CHI 2009: Reflecting on design, Boston, MA, USA, 4-9 April 2009

22. Glaser BG, Strauss AL (1967) The discovery of grounded theory: strategy for qualitative research. Aldine, Chicago
23. Gould JD, Lewis CH (1985) Designing for usability: key principles and what designers think. Commun ACM 28:300-311

24. Hamilton DL, Trolier TK (1986) Stereotypes and stereotyping: an overview of the cognitive approach. In: Gaertner SL, Dovidio JK (eds) Prejudice, discrimination and racism. Academic Press, New York, pp 127-157

25. Han K, Jung M, Cho J (2014) Implementation of the personal healthcare services on automotive environments. Pers Ubiquit Comput 18:523-533

26. Harrison CM (2004) Low-vision reading aids: reading as a pleasurable experience. Pers Ubiquit Comput 8:213-220

27. Hynes M, Wang H, McCarrick E et al (2011) Accurate monitoring of human physical activity levels for medical diagnosis and monitoring using off-the-shelf cellular handsets. Pers Ubiquit Comput 15:667-678

28. Iivari J, Iivari N (2011) Varieties of user-centredness: an analysis of four systems development methods. Inf Syst J 21:125-153

29. Joyce K, Loe M (2010) A sociological approach to ageing, technology and health. Sociol Health Illn 32:171-180

30. Joyce K, Williamson J, Mamo L (2007) Technology, science, and ageism: an examination of three patterns of discrimination. Indian J Gerontol 21:110-127

31. Katz S (2000) Busy bodies: activity, aging, and the management of everyday life. J Aging Stud 14:135-152

32. Kensing F, Greenbaum J (2013) Heritage. Having a say. In: Greenbaum J, Kyng M (eds) Design at work: cooperative design of computer systems. Lawrence Erlbaum Associates, Hillsdale, pp 21-36

33. Kim SC, Jeong YS, Park SO (2013) RFID-based indoor location tracking to ensure the safety of the elderly in smart home environments. Pers Ubiquit Comput 17:1699-1707

34. Kim Y-H, Lim I-K, Lee J-K (2014) A study on the algorithm to identify the abnormal status of a patient using acceleration algorithm. Pers Ubiquit Comput 18:1337-1350

35. Koufi V, Malamateniou F, Vassilacopoulos G (2010) A system for the provision of medical diagnostic and treatment advice in home care environment. Pers Ubiquit Comput 14:551-561

36. Kumar V (2013) 101 Design Methods. Wiley, New Jersey

37. Lessard L (2014) Reframing the socio-technical problem: a way forward for social informatics. In: Fichman P, Rosenbaum $\mathrm{H}$ (eds) Social informatics, Past, Present and Future. Cambridge Scholars Publishing, Cambridge, pp 136-151

38. Lézoray J-B, Segarra MT, Phung-Khac A et al (2011) A design process enabling adaptation in pervasive heterogeneous contexts. Pers Ubiquit Comput 15:353-363

39. Maekawa T, KishinoY Sakurai Y et al (2013) Activity recognition with hand-worn magnetic sensors. Pers Ubiquit Comput 17:1085-1094

40. Mäirä F, Soronen A, Koskinen I et al (2006) Probing a proactive home: challenges in researching and designing everyday smart environments. Human Technol 2:158-186

41. Maslow AH (1943) A theory of human motivation. Psychol Rev 50:370-396

42. McLean A (2011) Ethical frontiers of ICT and older users: cultural, pragmatic and ethical issues. Eth Inf Technol 13:313-326

43. Meza-Kubo V, Morán AL (2013) UCSA: a design framework for usable cognitive systems for the worried-well. Pers Ubiquit Comput 17:1135-1145

44. Mikkonen M, Väyrynen S, Ikonen V et al (2002) User and concept studies as tools in developing mobile communication services for the elderly. Pers Ubiquit Comput 6:113-124

45. Mort M, Roberts C, Callén B (2013) Ageing with telecare: care or coercion in austerity? Sociol Health Illn 35:799-812

46. Nardi BA, O'Day V (1999) Information ecologies: using technology with heart. MIT Press, Cambridge 
47. Neven L (2010) "But obviously not for me": robots, laboratories and the defiant identity of elder test users. Sociol Health Illn 32:335-347

48. Ordóñez FJ, de Toledo P, Sanchis A (2014) Sensor-based Bayesian detection of anomalous living patterns in a home setting. Pers Ubiquit Comput. doi:10.1007/s00779-014-0820-1

49. Orlikowski WJ (2007) Sociomaterial practices: exploring technology at work. Pers Ubiquit Comput 28:1435-1448

50. Park RC, Jung H, Shin DK et al (2014) Telemedicine health service using LTE-Advanced relay antenna. Pers Ubiquit Comput 18:1325-1335

51. Peine A, Faulkner A, Jæger B, Moors E (2015) Science, technology and the "grand challenge" of ageing-understanding the socio-material constitution of later life. Technol Forecast Soc Change 93:1-9

52. Peine A, Rollwgen I, Neven L (2014) The rise of the "innosumer"-rethinking older technology users. Technol Forecast Soc Change 82:199-214

53. Planinc R, Kampel M (2013) Introducing the use of depth data for fall detection. Pers Ubiquit Comput 17:1063-1072

54. Poulymenopoulou M, Malamateniou F, Vassilacopoulos G (2014) E-EPR: a workflow-based electronic emergency patient record. Pers Ubiquit Comput 18:91-100

55. Portet F, Vacher M, Golanski C et al (2013) Design and evaluation of a smart home voice interface for the elderly: acceptability and objection aspects. Pers Ubiquit Comput 17:127-144

56. Rodríguez MD, Roa JR, Morán AR et al (2013) CAMMInA: a mobile ambient information system to motivate elders to exercise. Pers Ubiquit Comput 17:1127-1134

57. Rogers Y, Marsden G (2013) Does he take sugar? Moving beyond the rhetoric of compassion. ACM Interact 20:48-57

58. Rogers Y, Paay J, Brereton M et al (2014) Never too old: engaging retired people inventing the future with MaKey MaKey. CHI 2014: SIGCHI Conference on human factors in computing systems, Toronto, Canada. 26 April-01 May 2014

59. Rogers Y, Sharp H, Preece J (2011) Interaction design. Beyond human-computer interaction, 3rd edn. Wiley, New Delhi

60. Schilit B, Adams N, Want R (1994) Context-aware computing applications. In: IEEE Workshop on mobile computing systems and applications, Santa Cruz, CA, US

61. Schilit BN, Theimer MM (1994) Disseminating active map information to mobile hosts. IEEE Netw 8:22-32

62. Schön DA (1983) The reflective practitioner-how professionals think in action. Basic Books, New York

63. Senger P, Boehner K, David S et al. (2005) Reflective design. AARHUS 2005: critical computing: between sense and sensibility, Arhus, Denmark. 21-25 August 2005

64. Schmidt DF, Boland SM (1986) Structure of perceptions of older adults: evidence for multiple stereotypes. Psychol Aging $1: 255-260$

65. Szymkowiak A, Morrison K, Gregor P et al (2005) A memory aid with remote communication using distributed technology. Pers Ubiquit Comput 9:1-5
66. Suchman LA (1987) Plans and situated actions: the problem of human-machine communication. Cambridge University Press, New York

67. Suchman LA (1994) Do categories have politics? CSCW 2:177-190

68. Vanden Abeele V, De Schutter B (2010) Designing intergenerational play via enactive interaction, competition and acceleration. Pers Ubiquit Comput 14:425-433

69. Van Kasteren TLM, Englebienne G, Kröse BJA (2010) An activity monitoring system for elderly care using generative and discriminative models. Pers Ubiquit Comput 14:489-498

70. Vassis D, Belsis P, Skourlas C et al (2010) Providing advanced remote medical treatment services through pervasive environments. Pers Ubiquit Comput 14:563-573

71. Vergados DD (2010) Service personalization for assistive living in a mobile ambient healthcare-networked environment. Pers Ubiquit Comput 14:575-590

72. Verlo M (2006) Multiple inequalities, intersectionality and the European Union. Eur J Women's Stud 13:211-228

73. Vines J, Pritchard G, Wright $P$ et al (2015) An age-old problem: examining the discourses of ageing in $\mathrm{HCI}$ and strategies for future research. ACM TOCHI 22:2-27

74. Walker A, Maltby T (2012) Active ageing: a strategic policy solution to demographic ageing in the European Union. Int J Soc Welf 21:S117-S130

75. Walter M, Eilebrecht B, Wartzek T et al (2011) The smart car seat: personalized monitoring of vital signs in automotive applications. Pers Ubiquit Comput 15:707-715

76. Weiser M (1991) The computer for the 21st century. Sci Am 265:66-75

77. Weiser M, Brown JS (1996) The coming age of calm technology. http://www.ubiq.com/hypertext/weiser/acmfuture2endnote.htm Accessed 27 November 2014

78. West D, Quigley A, Kay J (2007) MEMENTO: a digital-physical scrapbook for memory sharing. Pers Ubiquit Comput 11:313-328

79. Wilkinson CR, De Angeli A (2014) Applying user centred and participatory design approaches to commercial product development. Des Stud 35:614-631

80. Wilson C, Hargreaves T, Hauxwell-Baldwin R (2014) Smart homes and their users: a systematic analysis and key challenges. Pers Ubiquit Comput. doi:10.1007/s00779-014-0813-0

81. WHO-World Health Organization (2002) Active ageing: A policy framework, a contribution of the World Health Organization to the Second United Nations World Assembly on ageing. World Health Organization, Madrid

82. Yuan B, Herbert J (2014) Context-aware hybrid reasoning framework for pervasive healthcare. Pers Ubiquit Comput $18: 865-881$ 